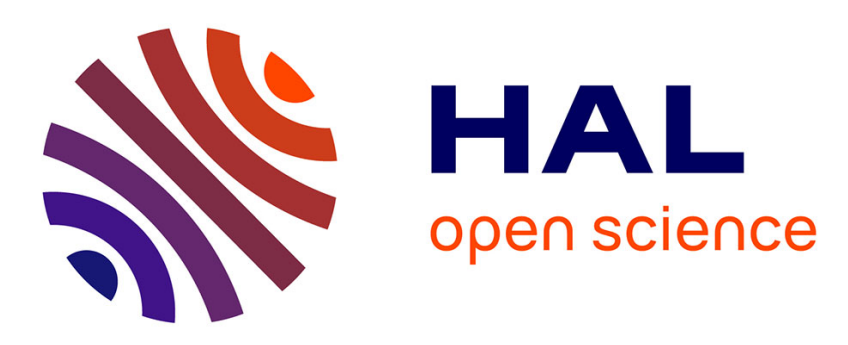

\title{
Analysis of gas adsorption in Kureha active carbon based on the slit-pore model and Monte-Carlo simulations
}

\author{
Nick Quirke, Martin Sweatman, Freek Kapteijn
}

\section{- To cite this version:}

Nick Quirke, Martin Sweatman, Freek Kapteijn. Analysis of gas adsorption in Kureha active carbon based on the slit-pore model and Monte-Carlo simulations. Molecular Simulation, 2006, 32 (07), pp.513-522. 10.1080/08927020600717095 . hal-00514981

\section{HAL Id: hal-00514981 \\ https://hal.science/hal-00514981}

Submitted on 4 Sep 2010

HAL is a multi-disciplinary open access archive for the deposit and dissemination of scientific research documents, whether they are published or not. The documents may come from teaching and research institutions in France or abroad, or from public or private research centers.
L'archive ouverte pluridisciplinaire HAL, est destinée au dépôt et à la diffusion de documents scientifiques de niveau recherche, publiés ou non, émanant des établissements d'enseignement et de recherche français ou étrangers, des laboratoires publics ou privés. 


\section{Molecular Simulation \\ Journal of \\ Experimental Nanoscience \\ $\because$ Taylor \& Francis \\ Taylor \& Francis Group}

\section{Analysis of gas adsorption in Kureha active carbon based on the slit-pore model and Monte-Carlo simulations}

\begin{tabular}{|r|l|}
\hline Journal: & Molecular Simulation/Journal of Experimental Nanoscience \\
\hline Manuscript ID: & GMOS-2005-0079.R1 \\
\hline Journal: & Molecular Simulation \\
\hline Date Submitted by the \\
Author: & 22-Mar-2006 \\
\hline Complete List of Authors: & $\begin{array}{l}\text { Quirke, Nick } \\
\text { Sweatman, Martin; University of Strathclyde, Department of } \\
\text { Chemical and Process Engineering } \\
\text { Kapteijn, Freek; Delft University of Technology, Reactor and } \\
\text { Catalysis Engineering }\end{array}$ \\
\hline Keywords: & Kureha , active carbon, pore size distribution \\
\hline
\end{tabular}

\section{SCHOLARONE ${ }^{\mathrm{m}}$ Manuscripts}




\title{
Analysis of gas adsorption in Kureha active carbon based on the slit-pore model and Monte-Carlo simulations
}

\author{
M.B. Sweatman ${ }^{\mathrm{a}}$, N. Quirke ${ }^{\mathrm{b}}$, W. Zhu ${ }^{\mathrm{c}}$ and F. Kapteijn ${ }^{\mathrm{c}}$ \\ ${ }^{a}$ Department of Chemical and Process Engineering, University of Strathclyde, Glasgow, G1 \\ 1XQ, Scotland, United Kingdom. \\ ${ }^{\mathrm{b}}$ Department of Chemistry, Imperial College, South Kensington, London, SW7 2AY, United \\ Kingdom.
}

${ }^{c}$ Reactor and Catalysis Engineering, DelftChemTech, Delft University of Technology, Julianalaan 136, 2628 BL Delft, The Netherlands.

\begin{abstract}
We analyse the adsorption of carbon dioxide and several light alkenes and alkanes on Kureha active carbon at a range of temperatures. We find generally good agreement between the alkene and alkane isotherms at moderate to high pressure, but find that at the lowest relative pressures for each gas there are significant discrepancies that seem to be correlated with the strength of gas - surface interactions. This pattern is similar to that observed in our previous work on the adsorption of light alkenes and alkanes on active carbon, except the errors here are much smaller. One possible explanation for this error is poor diffusion in the experiments at the lowest relative pressures, leading to measurements of non-equilibrium states. We suggest that this poor diffusion might be caused by potential barriers (i.e. it is activated diffusion) in the narrowest pores. We also find that our analysis of the adsorption of carbon dioxide at $273 \mathrm{~K}$ is inconsistent with all the alkene and alkane data. We suggest this discrepancy arises because our model of gas - surface interactions does not take contributions from polar surface sites into account. Although this study is specific to Kureha active carbon, we expect that our conclusions are relevant to other studies of gas adsorption on active
\end{abstract}


carbon; they highlight the need for great care when taking measurements at low pressures, and motivate improvements in molecular models for gas adsorption in active carbons.

\section{INTRODUCTION}

We are interested in understanding how to model a complex and important class of adsorption systems, i.e. active carbons. An important step towards this aim would be a fast and reliable method for predicting equilibrium gas adsorption on the basis of a straightforward characterisation. We aim to develop methods that allow the prediction of pure and mixed gas adsorption on the basis of one or more 'probe' adsorption isotherms.

In our early work [1, 2] we found that predictions could be improved, over standard techniques described in the literature [3-6], if Monte-Carlo simulation was used to model adsorption in pores, and if the porosity of the reference material (a low surface area carbon, Vulcan 3G) was taken into account. However, in later work [7, 8] we found that we could improve predictions dramatically, generally to within just a few percent for prediction of nitrogen and methane on the basis of a carbon dioxide probe isotherm (at ambient temperatures up to about 50 bar) if we used an active carbon as our reference material rather than a low surface area carbon. Our understanding of this finding is that generally the surfaces of active carbons [9, 10] (of which there are a multitude of different types, prepared from different precursors in different ways) are more similar to each other than to the surfaces of low surface area carbons (surface area aside, of course). Although a significant step forward in modelling procedures, this work should be seen in its proper context. That is, prediction of the adsorption of supercritical gases on the basis of the adsorption of a near-critical gas should not be seen as a particularly stringent test. A more interesting challenge is prediction of subcritical gas adsorption. To this end we recently reported [11] predictions for the adsorption of several light alkenes and alkanes at ambient temperatures on several quite different active carbons based, once again, on a carbon dioxide probe isotherm at $293 \mathrm{~K}$. The respective bulk critical temperatures of the gases involved are [12] $304 \mathrm{~K}, 191 \mathrm{~K}, 282 \mathrm{~K}, 305 \mathrm{~K}, 366 \mathrm{~K}$ and $370 \mathrm{~K}$ for carbon dioxide, methane, ethene, ethane, propene and propane respectively. We found a complex pattern of agreement. For carbons that had a wide range of pores, including some significant mesoporosity, we found good agreement between theory and experiment 
over a wide pressure range. However, for carbons with PSDs dominated by pore widths less than $1 \mathrm{~nm}$ we found considerably worse agreement, particularly at low pressure where errors were seen to be very large. For carbons with intermediate types of PSD the quality of agreement varied from reasonably good to poor, but again errors at low pressure were often very large. We attributed these errors to two main sources. First, we suggested that our procedures were sensitive to the polarity of active carbons and the moderately strong electrostatic quadrupole on carbon-dioxide (the other gases analysed have much smaller quadrupoles), but that the major errors seen at low pressure were caused by experimental error. That is, there seemed to be a strong correlation between these low pressure errors, the pore-size-distribution (PSD) and the molecular 'size' of the gas that we suggested could be caused by taking experimental measurements too quickly, i.e. before the system could reach equilibrium.

In this present work we analyse a different set of experimental data for adsorption of these gases (except methane) on Kureha active carbon. Our aim here is to test our modelling procedures on this new data. Overall, we find that agreement between theory and experiment is generally good for the alkenes and alkanes, comparable to the better results in reference [11] corresponding to carbons with some mesoporosity. However, we again find some inconsistency at the lowest relative pressures, although this is much reduced compared to most results in reference [11]. Moreover, we find a significant discrepancy between our analysis of the carbon dioxide isotherm at $273 \mathrm{~K}$ and all the other isotherms. We suggest that this is a result of not including polar gas - surface interactions in our models. In the following we provide a brief description of our experimental and modelling procedures, which are given in detail elsewhere[7, 8, 13-16]. We concentrate on analysis of our results.

\section{EXPERIMENTAL PROCEDURES}

The commercial sample, spherical bead activated carbon, was supplied by Kureha Chemical Industry. This activated carbon is referred to as Kureha active carbon. A Micromeritics ASAP 2010 gas adsorption analyser (stainless steel version) was used to measure the adsorption isotherms of ethene, ethane, propane, and propene on Kureha carbon in the pressure range from 0.002 to $120 \mathrm{kPa}$. The instrument was equipped with a turbomolecular vacuum pump 
and three different pressure transducers $(0.13,1.33$, and $133 \mathrm{kPa}$, respectively) to enhance the sensitivity in different pressure ranges. The static-volumetric technique was used to determine the volume of the gas adsorbed at different partial pressures: upon adsorption a pressure decrease was observed in the gas phase, which is a direct measure for the amount adsorbed.

The sample cell was loaded with $155.7 \mathrm{mg}$ of Kureha carbon particles. Prior to the adsorption measurements the adsorbent particles were outgassed in situ in vacuum at $623 \mathrm{~K}$ for $16 \mathrm{~h}$ to remove any adsorbed impurities. The obtained dry sample weight was used in the calculation of isotherm data.

The gaseous adsorbates such as ethene, ethane, propane, and propene were 3.5 grade $(>99.95 \%)$.

\section{MODELLING PROCEDURES}

As in previous work [7, 8], we employ the polydisperse independent ideal slit-pore model to model the surface of active carbons. The pore-size distribution (PSD) is calculated by analysis of a single experimental probe adsorption isotherm according to the adsorption equation

$N(P)=\int_{0}^{\infty} d H f(H) v(H, P)$

where $N$ is the excess adsorption (after subtraction of a helium calibrated pore volume, which we model by setting the 'chemical' pore width $H=H_{p}-0.285 \mathrm{~nm}$ ), $P$ is pressure, $H$ is slitpore (chemical) width $\left(H_{p}\right.$ is 'physical' pore width defined as the distance between atom centres in the first layer of opposing slit-pore walls), $f$ is the PSD and $v$ is a kernel of local isotherms for each pore width. Adsorption isotherms for other gases are then predicted using the appropriate kernel with the same PSD. The PSD is obtained using the procedures described in reference [7], i.e. the PSD is constrained to a sum of log-normal modes, and a downhill simplex algorithm is applied to obtain the smoothest PSD that produces a fit to the experimental adsorption isotherm within experimental error. The PSD is defined over a range of pore widths consistent with the 1 of the probe gas, as described previously [7] and by 


\begin{abstract}
Seaton and colleagues[17]. So in this work we limit the PSD to the range $0.315 \leq H_{c} \leq 2.715$ $\mathrm{nm}$, and, for convenience, at most 3 log-normal modes.
\end{abstract}

We use Monte-Carlo simulation[18] to generate the appropriate kernels[19]. We model gas molecules as rigid assemblies of Lennard-Jones and partial charge sites. We tailor the Lennard-Jones (LJ) parameters until good agreement with experimental data for saturation properties (coexisting gas and liquid densities and pressures) is obtained by Gibbs ensemble simulation[18, 20,21]. We employ a cutoff in gas-gas interactions to avoid interactions between periodic images, and also use a 'ramp' [7] (starting at 0.9 times the cutoff distance) to smooth these interactions near the cutoff. Our gas molecular models are identical to those used in preceding work $[7,11]$ and are detailed in Table 1. Gibbs ensemble Monte Carlo simulation data for the saturation properties of the ethene, ethane, propene and propane models are displayed in Figures 1a-d (similar data for carbon dioxide can be found in reference [7]) and compared with reference data[12].

Our slit pores are formed from two identical opposing walls, whose mass centres are separated by a 'physical' pore width $H_{p}$, each described by the Steele potential [14, 22, 23]. If we use the Lorentz-Berthelot combining rules [14] then for a given gas molecular model our surface model is fully defined by definition of the surface - surface interaction length and strength parameters respectively. The length parameter is fixed at the commonly used value of $0.34 \mathrm{~nm}$ while the strength parameter is adjusted, or calibrated [7], separately for each gas.

We use grand canonical ensemble Monte-Carlo simulations to generate the appropriate kernels for adsorption in slit-pores at the required temperatures. That is, we have generated kernels for all the gases in this study at $273 \mathrm{~K}$, and for ethene and ethane at $194 \mathrm{~K}$. To predict adsorption of ethene and ethane at $298 \mathrm{~K}$ we use the same $293 \mathrm{~K}$ kernels generated for previous work [7], and then use our 'slab-DFT' methodology [7, 13] to convert these databases from $293 \mathrm{~K}$ to $298 \mathrm{~K}$. We use the same gas molecular models calibrated to reproduce bulk fluid saturation properties in our slit-pore simulations.

Gas - surface interactions for these gases were calibrated in previous work [7, 11] by fitting to PNC active carbon on the basis of a PSD generated from a carbon dioxide probe isotherm, 
with the surface - surface interaction strength for nitrogen held fixed at the commonly used value of $\varepsilon_{s s} / k_{B}=28.0 \mathrm{~K}$. However, these gas-surface calibrations were performed at $293 \mathrm{~K}$, while the data set under analysis here comprises adsorption isotherms at a range of temperatures. Specifically, ethene and ethane at $194 \mathrm{~K}$ and $298 \mathrm{~K}$, and all the gases at $273 \mathrm{~K}$. We expect our calibration procedure at $293 \mathrm{~K}$ to remain accurate (i.e. we expect to be able to use the same values for $\varepsilon_{s s}$ ) at $273 \mathrm{~K}$, but for ethene and ethane at $194 \mathrm{~K}$ we have performed a separate calibration study. For each respective gas at $194 \mathrm{~K}$, we tailored $\varepsilon_{s s}$ until good agreement was obtained for adsorption at $273 \mathrm{~K}$ and $298 \mathrm{~K}$ (using the values for $\varepsilon_{s s}$ obtained in earlier work for $293 \mathrm{~K}$ ) on the basis of a PSD generated by the respective $194 \mathrm{~K}$ isotherm. The results of this calibration exercise are also recorded in Table 1. Figure 2a shows how the predicted adsorption of ethene at $273 \mathrm{~K}$ and $298 \mathrm{~K}$ varies with the strength of $\varepsilon_{s s}$ at $194 \mathrm{~K}$. Figure $2 \mathrm{~b}$ shows the corresponding variation for ethane, while Figure $2 \mathrm{c}$ shows the variation in the PSD, generated using the method described above.

Figure $2 \mathrm{a}$ shows that at moderate and higher pressures the prediction of ethene at $273 \mathrm{~K}$ and $298 \mathrm{~K}$ is more accurate when $\varepsilon_{s s} / k_{B}=28.5 \mathrm{~K}$ at $194 \mathrm{~K}$, compared to $\varepsilon_{s s} / k_{B}=28.0 \mathrm{~K}$ which is the value calibrated in reference [7] and used to generate the $273 \mathrm{~K}$ and $298 \mathrm{~K}$ databases. Similarly, Figure $2 \mathrm{~b}$ shows that for ethane $\varepsilon_{s s} / k_{B}=26.5 \mathrm{~K}$ at $194 \mathrm{~K}$ is better than $\varepsilon_{s s} / k_{B}=25.5$ $\mathrm{K}$, or $\varepsilon_{s S} / k_{B}=23.0 \mathrm{~K}$. However, in the insets to these Figures it can be seen that the predictions at low pressure are not as good, i.e. there is consistent under-prediction of ethene, and especially ethane, at $273 \mathrm{~K}$ and $298 \mathrm{~K}$ on the basis of the PSDs generated from the respective $194 \mathrm{~K}$ isotherms, except for ethane when $\varepsilon_{s s} / k_{B}=23.0 \mathrm{~K}$ at $194 \mathrm{~K}$. For this value of $\varepsilon_{s s}$ at 194 $\mathrm{K}$ we find that ethane adsorption at 273 and $298 \mathrm{~K}$ is well predicted at low pressure, but not at moderate or higher pressure. So, we find that it is not possible to accurately reproduce the entire isotherms at $273 \mathrm{~K}$ and $298 \mathrm{~K}$ using the $194 \mathrm{~K}$ isotherms as probes. We will come back to this point later.

\section{ANALYSIS OF ADSORPTION ISOTHERMS}

Our data set of adsorption isotherms on Kureha active carbon consists of ethene and ethane at $194 \mathrm{~K}, 273 \mathrm{~K}$ and $298 \mathrm{~K}$, and propene, propane and carbon dioxide at $273 \mathrm{~K}$. The $194 \mathrm{~K}$ isotherms and the propene and propane isotherms are measured from very low pressure $\left(\sim 10^{-}\right.$ 
${ }^{5}$ bar). All isotherms are measured up to 1.2 bar. This upper pressure limit corresponds to relative press $-\rho$ relative to the saturation pressure) of 0.34 and 0.73 for ethene and ethane at $194 \mathrm{~K}, 0.029$, v.v $0,0.206,0.254$ and 0.035 for ethene, ethane, propene, propane, and carbon dioxide at $273 \mathrm{~K}$ respectively, and 0.029 for ethane at $298 \mathrm{~K}$. Ethene is supercritical at $298 \mathrm{~K}$. This means that we should expect the ethane isotherm at $194 \mathrm{~K}$ to be the most sensitive probe of porosity, followed by ethene at $194 \mathrm{~K}$. Not only are gas - surface interactions more significant at this temperature, but the range of pore widths that can be resolved with capillary condensation is greatest (compared to the other gases studied here) at this temperature and upper pressure limit. This temperature is well above the bulk triple point temperature $(90 \mathrm{~K}$ for ethane), so freezing should not cause a problem here, as might be the case with nitrogen at $77 \mathrm{~K}$ for example [2, 14, 19]. Because of the relatively low upper pressure limit the carbon dioxide isotherm carries limited information. So, unfortunately, we cannot use the carbon dioxide isotherm as the main probe, which means that we cannot be entirely consistent with our previous work [7].

Figures $3 \mathrm{a}$ and $3 \mathrm{~b}$ show theoretical predictions compared with experiment for adsorption on Kureha active carbon based on PSDs generated by fitting to ethene and ethane respectively at 194 K. In Figure 3a it can be seen that ethane adsorption at $194 \mathrm{~K}$ at the lowest pressures is significantly over-predicted, while it is generally good at moderate pressures and higher. The propene and propane isotherms at $273 \mathrm{~K}$ are well predicted over the whole pressure range. Ethene and ethane are predicted quite well at $273 \mathrm{~K}$, although there is a degree of underprediction at the lowest relative pressures. Carbon dioxide at $273 \mathrm{~K}$ is significantly underpredicted at the lowest relative pressures, although agreement improves at higher pressures. Overall, these are satisfactory results, except for ethane at $194 \mathrm{~K}$ and carbon dioxide at $273 \mathrm{~K}$ at the lowest relative pressures. The situation in Figure $3 \mathrm{~b}$ is not as good, particularly at the lowest relative pressures. Although predictions for all gases and temperatures are acceptable at moderate to high pressures, at the lowest pressures there is consistent under-prediction.

Figure 2c compares the PSDs from this analysis; we will use it to help interpret these results. We are interested here in comparing the solid lines with (ethene) and without (ethane) the solid symbols. The most obvious conclusion from this analysis is that there are some pores, less than about 6.0 $\mathrm{A}$ in width, that ethane at $194 \mathrm{~K}$ at low pressure has not accessed, 
compared to ethene at $194 \mathrm{~K}$. However, the pore volume calculated from the PSDs is slightly larger for ethane $\left(0.568 \mathrm{~cm}^{3} / \mathrm{g}\right)$ than for ethene $\left(0.553 \mathrm{~cm}^{3} / \mathrm{g}\right.$ ) (note that in reference [16] the reported pore volume of Kureha active carbon is higher because the bulk molar volume of the respective adsorbate at its saturated liquid density is used in the analysis). So it appears that these small pores, which are not accessed by ethane at $194 \mathrm{~K}$ at the lowest pressures, are actually filled at higher pressure and interpreted as slightly wider pores, i.e. as being $6.5 \mathrm{~A}$ in width. Generally, the agreement between the PSDs corresponding to ethene and ethane at 194 $\mathrm{K}$ is good, with both PSDs having secondary and tertiary peaks at about 8.5 to $9.5 \mathrm{~A}$ and 14.0 to 15.0 A respectively. Of course, to make these detailed comparisons requires our modelling and gas-surface interaction calibration procedures to be accurate. That alkene and alkane isotherms across a wide range of temperatures seem to be consistent at moderate pressure and higher indicates that this is so, but we should not be too confident in this analysis given the simplicity of our surface model. This is highlighted by the apparent inconsistency between the carbon dioxide isotherm and the other isotherms.

To analyse this data further, Figure 4 a shows prediction versus experiment when the PSD is fitted simultaneously to both ethene at $194 \mathrm{~K}$ and carbon dioxide at $273 \mathrm{~K}$, with equal weighting. Once again the most serious error is for ethane at $194 \mathrm{~K}$ and the lowest pressures, which is significantly over-predicted. Interestingly, predictions for all the other isotherms, including the fit to carbon dioxide at $273 \mathrm{~K}$, are reasonably good over the whole range of pressures. To explain this result we again consider the PSD generated from this simultaneous fitting exercise, shown in Figure 4b. If we analyse this result in the same terms as before, we should conclude that carbon dioxide at $273 \mathrm{~K}$ is accessing many pores about 3.5 Angstroms in width that the other gasses cannot access. Physically, it might be thought that these pores correspond to the inter-layer distance in graphite, and are formed where a portion of a layer is absent in a stack of graphene layers. However, if such pores exist then, using an interlayer distance of 3.35 Angstroms for graphite, their chemical pore width would be 3.85 Angstroms according to the definition of chemical pore width used here (remember, we use $H=H_{p}$ $0.285 \mathrm{~nm}$ ). So in our view there is no physical reason to expect a significant fraction of pores with chemical width 3.5 Angstroms to exist in any active carbon. In our view, this first peak at about 3.5 $\mathrm{A}$ in Figure $4 \mathrm{~b}$ is an artefact of our surface model; by introducing such a peak into the PSD our model is able to account for the observed behaviour of the carbon dioxide 
and other isotherms (except for ethane at $194 \mathrm{~K}$ ). It can achieve this because at about 3.5 Angstroms the low pressure adsorption of ethene and ethane changes from being weak to strong, whereas the adsorption of carbon dioxide is already strong at this pressure (this is simply a steric effect, concerned with how easy it is to 'fit' a given molecule inside such narrow pores). Conversely, ethene and ethane can easily fit into 3.85 Angstrom pores. We instead interpret this peak in the PSD as a signal of a deficiency in our surface model. We suspect, this deficiency arises because of the lack of polar surface sites in our model that could interact strongly with the relatively large (compared to the other gases) permanent electric quadrupole of carbon dioxide. This is the most significant differentiating factor between carbon dioxide, and the alkenes and alkanes that we know of. Essentially, we suspect that carbon dioxide's quadrupole might well be interacting quite strongly with polar sites on the active carbon surface that are interpreted by the slit pore model as narrow pores.

\section{DISCUSSION}

Overall, the level of agreement between theoretical prediction and experiment, at least for the alkanes and alkenes, shown in Figures 2a, 2b, 3a and $3 b$ is encouraging. The slit-pore model has been subjected to a more demanding test than in our previous work [7], and overall it has performed quite well. Consistency between isotherms of near-supercritical and substantially sub-critical gases is generally good, except for some remaining errors that we will discuss below. Indeed, it might be surprising to see this level of agreement considering the simplicity of the slit-pore model. It is tempting to conclude that these results indicate that the slit-pore model is not such a gross approximation for some active carbons after all. The main approximations of this model concern the independence and uniformity of the pores, the 'universality' of the PSD for all gases, temperatures and pressures, the use of the Steele potential to represent gas-surface interactions, and the use of gas molecular models tuned to reproduce bulk fluid behaviour to model adsorption in slit pores. For Kureha active carbon these choices appear to be quite reasonable, possibly because for this material and these gases adsorption is dominated by gas-surface interactions, and we have calibrated these interactions for each gas. Any imperfections in the model, i.e. the absence of pore non-uniformity and pore-pore interactions[14], non-universality of the PSD, use of the Steele potential etc., are largely compensated by this calibration procedure. But we should be careful about drawing 
wider conclusions regarding the use of our procedures to model other materials where such factors might have more influence.

Regarding the remaining errors, we suspect that the low pressure experimental measurements for all the gases, and particularly ethane at $194 \mathrm{~K}$, might be in error, resulting from poor diffusion. A potential mechanism for this error arises from the same source that seems to make the slit-pore model so surprisingly successful, that is, diffusion (as well as adsorption) is dominated by gas-surface interactions. In such narrow pores as occur in the present material, pore sizes frequently correspond to only one or two adsorbed layers. The external potential, (i.e. the gas-surface interaction), $V^{\text {ext }}$, in these pores is large and negative, and its effect is enhanced as temperature decreases, i.e. as molecular thermal energy reduces. If there is Comment [c3]: change made significant variation in the Boltzmann factor $\left(\exp \left(-V^{e x t} / k_{B} T\right)\right)$ along a diffusion path then the diffusion will effectively become 'activated diffusion' [18], i.e. it will be controlled by the number and severity of the 'potentic " carbon material will be influenced $1 \equiv$; number and type of non-uniformities present in these narrowest pores, including pore junctions, openings, pits, constrictions etc., which would act like a network of resistors in an electrical circuit. To justify this interpretation, consider estimates (shown in Table 2) of the natural logarithm of the Boltzmann factor for each gas and temperature on a single surface defined by our surface model. The estimates in Table 2 indicate that, if we accept this explanation, then we should expect similar behaviour for ethene and ethane at $194 \mathrm{~K}$ and propene and propane at $273 \mathrm{~K}$, and for ethene, ethane and carbon dioxide at $273 \mathrm{~K}$. Looking again at Figure 3a, we see that the low pressure behaviour of ethene at $194 \mathrm{~K}$ and propene and propane at $273 \mathrm{~K}$ does appear to be consistent. However, ethane at $194 \mathrm{~K}$ appears to be inconsistent with this hypothesis in that it seems to be much less mobile at the lowest pressures in Kureha active carbon than ethene at $194 \mathrm{~K}$ or propene and propane at $273 \mathrm{~K}$. To be clear, in Figure $3 \mathrm{a}$ while theory and experiment agree, even at low pressure, for ethane at $194 \mathrm{~K}$ and propene and propane at $273 \mathrm{~K}$, theory and experiment do not agree at the lowest pressures for ethane at $194 \mathrm{~K}$. We cannot explain this within our hypothesis. Of course, diffusion in nanoporous materials is a very complex process and is influenced, like adsorption, by fine details of both pore geometry and adsorbate molecular model [24, 25]. Nevertheless, we cannot explain the difference seen in the low-pressure adsorption of ethane at $194 \mathrm{~K}$ compared to the other gases. In particular, we cannot account 
for the differences seen between ethene and ethane at $194 \mathrm{~K}$, and ethane at $194 \mathrm{~K}$ and $273 \mathrm{~K}$. To be clear, we cannot explain why the level of agreement at low pressure between theory and expr it for ethene at $194 \mathrm{~K}$ and ethene and ethane at $273 \mathrm{~K}$ seems to support our hyp ; regarding activated diffusion at low pressure, while the poor agreement between theory and experiment at low pressure for ethane at $194 \mathrm{~K}$ does not. Note that this discrepancy cannot be due solely to any difference between ethene and ethane (for example, any specific difference in gas-surface interactions), because it also occurs for ethane at two different temperatures (194 K and $273 \mathrm{~K}$ ). This means that it can only be caused by inconsistencies in experimental measurement techniques, or by a process that applies only to ethane adsorption at low temperature and pressure of which we are unaware.

In our view, this diffusion mechanism does not explain the inconsistency between carbon dioxide and the other gases because there is little difference between the factors in Table 2 for carbon dioxide, ethene and ethane at $273 \mathrm{~K}$. In addition, because these molecules are of a reasonably similar size it seems unlikely to us that molecular sieving could be significant. A simple estimate of the interaction energy of a carbon dioxide molecule on a graphitic surface with an embedded point dipole of 1 Debeye shows that the surface dipole - gas molecule electrostatic quadrupole interaction energy can amount to as much as $20 \%$ of the total interaction energy, depending on pore width and molecular orientation. This is a significant contribution that will, of course, scale linearly with the size of the embedded dipole. So it is clear that the polarity of the surface should be included in the surface model if the adsorption of gases with significant permanent electric quadrupoles, such as carbon dioxide, or dipoles, such as water, are to be modelled.

Similar conclusions have been reached recently [26] in respect of surface quadrupole - gas molecule dipole interactions. Zhao and Johnson [26] provided details of how the interaction of polar adsorbate molecules with the permanent electric quadrupole (and any induced, or image, dipole) of carbon in graphitic walls can be represented in an efficient yet accurate manner in terms of effective potentials. Their effective potentials are developed by techniques very similar to the original Steele potential for Lennard-Jones interactions, resulting in 'smeared' or surface averaged effective potentials. They find that these interactions are significant for strongly dipolar and quadrupolar adsorbate molecules. These particular 
electrostatic contributions to the total energy, resulting from adsorbate interactions with the permanent quadruple of carbon in graphitic walls, are effectively included in our molecular models by our gas - surface calibration procedure. But their work does suggest an efficient method that could accoint for the interaction of polar adsorbate molecules with the permanent electric dipoles or qui les of impurities, or active sites, that are known to occur in varying quantities in active carbons [27], provided these impurities have sufficiently high surface density. A high surface density is desired in this case because of the surface averaging technique employed. If the surface density is not sufficiently high then this approach could lead to inaccuracies because the real external potential would have highly localised sites, whereas this averaging procedure leads to an average 'smooth' potential, and these different situations can lead to different adsorption phenomena, depending on the temperature.

Alternatively, explicit dipolar or quadrupolar surface sites could be included in the surface model. This is the approach described by Jorge and Seaton [28] who represent all such 'active sites' in terms of $\mathrm{C}=\mathrm{O}$ surface groups, and use grand canonical MC simulation to determine the adsorption kernel, $v(H, P)$, (see equation 1) of water and ethane in slit pores with distributions of these sites. They then use the pure isotherms of water and ethane to characterise BPL active carbon in terms of a PSD and a distribution of active surface sites. To our knowledge, this is the first time that this technique, i.e. combining the slit-pore model with a model of active surface sites, MC simulation of adsorption, and differential adsorption of polar and non-polar adsorbates, has been attempted to characterise an active carbon. They find that this approach is able to predict co-adsorption of water and ethane on BPL active carbon quite well, and much better than theories based on, for example, ideal adsorbed solution theory (IAST). Unfortunately, they also find that satisfactory accuracy can only be achieved if the density of active surface sites is allowed to depend on pore width, which produces significant additional model complexity and contradicts other work [29] using more empirical methods. In our view, their results for water adsorption are likely to be sensitive to their particular PSD, which in turn is sensitive to their particular choice of ethane and graphitic wall molecular models (Figures $2 \mathrm{a}$ to $2 \mathrm{c}$ in this work demonstrate the sensitivity of the PSD to molecular model parameters), and they did not analyse this sensitivity. So it is still conceivable that a pore-width independent distribution of active surface sites could be sufficient in such a model for characterisation studies, and further work should be performed 


\begin{abstract}
to examine this. Of course, explicit representation of these polar surface sites is possible with more detailed 3D surface models as well [30, 31]. But to our knowledge, this 'reverse MonteCarlo' approach has not been employed to characterise, or make adsorption predictions, for active carbons.
\end{abstract}

Whichever approach is adopted, the conclusion of this work is that surface models that account for surface polarity are necessary for accurate description of the adsorption of carbon dioxide in active carbons at ambient temperatures. Very likely, they will be important for other strongly quadrupolar gases as well, and are not only useful for describing the adsorption of strongly dipolar gases. So it seems, after all, that carbon dioxide is not such a good probe of active carbons because it cannot by itself distinguish between adsorption on polar sites and in slit-pores of various widths. This clearly did not present a problem in our earlier work where we were interested in predicting the adsorption of super-critical gases such as nitrogen and methane at $293 \mathrm{~K}$. But for subcritical adsorption it becomes more important to distinguish competing effects, because such adsorption is more sensitive to these effects. This work also highlights the need for care when interpreting $77 \mathrm{~K}$ nitrogen adsorption measurements. At this temperature there has been speculation $[2,14,15]$ that nitrogen could potentially freeze, or at least become glassy or highly viscous, in the narrowest pores in active carbons. This speculation is based on analysis of data in work of Radhakrishnan et.al. [32]. Further, $-V^{\text {ext }} /$ $k_{B} T$ for this gas at this temperature is 15.2 , based on the nitrogen model in reference [7], which is significantly higher than any of the values in Table 2. So if low pressure adsorption measurements are sensitive to activated diffusion, as is proposed above in relation to results shown here in Figures 3 and 4a, then great care should be exercised with interpreting $77 \mathrm{~K}$ nitrogen adsorption. Moreover, nitrogen has an electrostatic quadrupole moment about $1 / 3^{\text {rd }}$ the size of carbon dioxide's (according to the molecular models in [7]), which indicates that electrostatic interactions could also play a significant role in its adsorption in active carbons.

From a purely theoretical perspective, it appears that an inert gas, like argon, which is quite small, spherical and non-polar should be used to characterise pore geometries in active carbons. In this case, a temperature of about $120 \mathrm{~K}$, which is about half way between argon's triple and critical points and, using the model of argon in [33], has a corresponding Boltzmann factor of about 9.2, could be used. Alternatively, a small non-polar organic gas, 
such as ethane (as used by Jorge and Seaton [28]) could be employed at an appropriate temperature. Water could then be used to characterise surface polarity.

\section{AcknowledgementsThis work was performed as part of the EU Network of Excellence,}

'Inside-Pores' ( see http://www.pores.gr)

\section{References}

[1] Sweatman, M.B. and Quirke, N. (2000) "Characterization of porous materials at ambient temperatures and high pressure", J. Phys. Chem. B 105, 1403.

[2] Sweatman, M.B. and Quirke, N. (2001) "Characterization of porous materials by gas adsorption: Comparison of Nitrogen at $77 \mathrm{~K}$ and carbon dioxide at $298 \mathrm{~K}$ for activated carbon", Langmuir 17, 5011.

[3] Lastoskie, M.L., Gubbins, K.E., and Quirke, N. (1993) "Pore-size distribution analysis of microporous carbons - a density functional theory approach", J. Phys. Chem. 97, 4786.

[4] Lastoskie, M.L., Gubbins, K.E., and Quirke, N. (1993) "Pore-size heterogeneity and the carbon slit pore - a density functional theory model", Langmuir 9, 2693.

[5] Seaton, N.A., Walton, J.P.R.B., and Quirke, N. (1989) "A new analysis method for the determination of the pore-size distribution of porous carbons from nitrogen adsorption measurements", Carbon 27, 853.

[6] Dombrowski, R.J., Hyduke, D.R., and Lastoskie, M.L. (2000) "Pore size analysis of activated carbons from argon and nitrogen porosimetry using density functional theory", Langmuir 16, 5041.

[7] Sweatman, M.B. and Quirke, N. (2005) "Gas adsorption in active carbons and the slit-pore model 1: Pure gas adsorption", J. Phys. Chem. B 109, 10381.

[8] Sweatman, M.B. and Quirke, N. (2005) "Gas adsorption in active carbons and the slit-pore model 2: Mixture adsorption prediction with DFT and IAST", J. Phys. Chem. B 109, 10389.

[9] Bansal, R.C., Donnet, J., and Stoeckli, F. (1988), Active Carbon (Marcel Dekker, New York).

[10] Jankowska, H., Swiatkowski, A., and Choma, J. (1991), Active Carbon (Ellis Horwood, New York).
Comment [c11]: Is this actually

appropriate given that I performed most of the analysis, wrote most of the paper, but am not yet part of the NOE? 
[11] Sweatman, M.B., Quirke, N., and Pullumbi, P. (in press) "Predicting ambient temperature adsorption of gases in active carbons", Stud. Surf. Sci. Catal.

[12] Thermophysical properties of fluid systems. NIST Chemistry WebBook 2005; http://webbook.nist.gov/chemistry/fluid/.

[13] Sweatman, M.B. and Quirke, N. (2002) "Predicting the adsorption of gas mixtures: density functional theory versus adsorbed solution theory", Langmuir 18, 10443.

[14] Sweatman, M.B. and Quirke, N. (2005) "Modelling gas adsorption in nanoporous amorphous adsorbents", in Handbook of Theoretical and Computational Nanotehnology, Ed. W. Schommers and M. Rieth, (American Scientific Publishers).

[15] Sweatman, M.B. and Quirke, N. (2005) "Modelling gas mixture adsorption in active carbons", Mol. Sim. 31, 667.

[16] Zhu, W., Groen, J.C., Van Miltenburg, A., Kapteijn, F., and Moulijn, J.A. (2005)

"Comparison of adsorption behaviour of light alkanes and alkenes on Kureha activated carbon", Carbon 43, 1416.

[17] Davies, G.M., Seaton, N.A., and Vassiliadis, V.S. (1999) "Calculation of pore size distributions of activated carbons from adsorption isotherms", Langmuir 15, 8235.

[18] Smit, B. and Frenkel, D. (1996), Understanding molecular simulation: from algorithms to applications (Academic, New York).

[19] Sweatman, M.B. and Quirke, N. (2001) "Modelling gas adsorption in slit-pores using Monte Carlo simulation", Mol. Sim. 27, 295.

[20] Panagiotopoulos, A.Z. (1987) "Direct determination of phase coexistence properties by Monte-Carlo simulation in a new ensemble", Mol. Phys. 61, 813.

[21] Panagiotopoulos, A.Z., Quirke, N., Stapleton, M., and Tildesley, D.J. (1988) "Phaseequilibria by simulation in the Gibbs ensemble - alternative derivation, generalization and application to mixture and membrane equilibria", Mol. Phys. 63, 527.

[22] Steele, W.A. (1973) "The physical interaction of gases with crystalline solids", Surf. Sci. 36, 317 .

[23] Steele, W.A. (1974), The Interaction of Gases with Solid Surfaces (Pergamon, Oxford).

[24] Travis, K.P. and Gubbins, K.E. (2001) "Computer simulation of isothermal mass transport in graphite slit pores", Mol. Sim. 27, 405.

[25] MacElroy, J.M.D., Friedman, S.P., and Seaton, N.A. (1999) "On the origin of transport resistances within carbon molecular sieves ", Chem. Eng. Sci. 54, 1015. 
[26] Zhao, X.C. and Johnson, J.K. (2005) "An effective potential for adsorption of polar molecules on graphite", Mol. Sim. 31, 1.

[27] Burg, P., Abraham, M.H., and Cagniant, D. (2003) "Methods of determining polar and non-polar sites on carbonaceous adsorbents. The contribution of the linear solvation energy relationship approach", Carbon 41, 867.

[28] Jorge, M. and Seaton, N.A. (2003) "Predicting adsorption of water/organic mixtures using molecular simulation", AICHE 49, 2059.

[29] Slasli, A.M., Jorge, M., Stoeckli, F., and Seaton, N.A. (2004) "Modelling of water adsorption by activated carbons: effects of microporous structure and oxygen content", Carbon 42, 1947.

[30] Pikunic, J., Clinard, C., Cohaut, N., Gubbins, K.E., Guet, J.M., Pellenq, R.J.M., Rannou, I., and Rouzaud, J.N. (2003) "Structual modelling of porous carbons: constrained reverse Monte Carlo method", Langmuir 18,

[31] Thomson, K.T. and Gubbins, K.E. (2000) "Modelling structural morphology of microporous carbons by reverse Monte Carlo", Langmuir 16, 5761.

[32] Radhakrishnan, R., Gubbins, K.E., and Sliwinska-Bartkowiak, M. (2002) "Global phase diagrams for freezing in porous media", J. Chem. Phys. 116, 1147.

[33] Cracknell, R.F. and Gubbins, K.E. (1993) "Molecular simulation of adsorption and diffusion in VPI-5 and other aluminophosphates", Langmuir 9, 824. 


\section{Page 17 of 26}

Table 1

Model parameters used in MC simulations. $\sigma_{f f}$ and $\varepsilon_{f f}$ are the Lennard-Jones interaction length and energy parameters respectively, $L$ and $\theta$ denote bond lengths and angles respectively, $q$ is the partial charge centred on a Lennard-Jones site, $r_{c}$ denotes the cutoff distance between molecular centres (the $\mathrm{CH}$ site in the case of propene), while $\varepsilon_{s s}$ is the calibrated strength of surface - surface interactions.

\begin{tabular}{lccccc}
\hline Parameter & $\mathrm{CO}_{2}$ & $\mathrm{C}_{2} \mathrm{H}_{4}$ & $\mathrm{C}_{2} \mathrm{H}_{6}$ & $\mathrm{C}_{3} \mathrm{H}_{6}$ & $\mathrm{C}_{3} \mathrm{H}_{8}$ \\
\hline$\sigma_{f f}(\mathrm{~nm})$ & $\mathrm{C}: 0.275$ & $\mathrm{CH}_{2}: 0.3483$ & $\mathrm{CH}_{3}: 0.3625$ & $\mathrm{CH}_{3}: 0.3561$ & $\mathrm{CH}_{3}: 0.3608$ \\
& $\mathrm{O}: 0.304$ & & & $\mathrm{CH}: 0.3431$ & $\mathrm{CH}_{2}: 0.3458$ \\
& & & & $\mathrm{CH}_{2}: 0.3391$ & \\
\hline$L(\mathrm{~nm})$ & $\mathrm{C}-\mathrm{O}:$ & $\mathrm{CH}_{2}-\mathrm{CH}_{2}:$ & $\mathrm{CH}_{3}-\mathrm{CH}_{3}:$ & $\mathrm{CH}_{3}: 0.1936$ & $\mathrm{CH}_{3}-\mathrm{CH}_{2}:$ \\
& 0.1149 & 0.1922 & 0.1976 & $\mathrm{CH}: 0$ & 0.1966 \\
& & & & $\mathrm{CH}_{2}: 0.1896$ & \\
\hline$\theta(\mathrm{deg})$ & $\mathrm{O}-\mathrm{C}-\mathrm{O}: 0$ & 0 & 0 & $\mathrm{CH}_{3}-\mathrm{CH}_{-}-\mathrm{CH}_{2}:$ & $\mathrm{CH}_{3}-\mathrm{CH}_{2}-\mathrm{CH}_{3}:$ \\
& & & & 124.0 & 114.0 \\
\hline$r_{c}(\mathrm{~nm})$ & 1.5 & 1.6 & 1.6 & 1.75 & 1.75 \\
\hline$\varepsilon_{f f} / k_{B}(\mathrm{~K})$ & $\mathrm{C}: 28.3$ & $\mathrm{CH}_{2}: 112.6$ & $\mathrm{CH}_{3}: 121.3$ & $\mathrm{CH}_{3}: 122.8$ & $\mathrm{CH}_{3}: 123.4$ \\
& $\mathrm{O}: 84.2$ & & & $\mathrm{CH}_{0}: 92.6$ & $\mathrm{CH}_{2}: 88.7$ \\
& & & & $\mathrm{CH}_{2}: 112$ & \\
\hline$q(\mathrm{e})$ & $\mathrm{C}: 0.6512$ & $\mathrm{CH}_{2}: 0$ & $\mathrm{CH}_{3}: 0$ & $\mathrm{CH}_{3}: 0$ & $\mathrm{CH}_{3}: 0$ \\
& $\mathrm{O}:-0.3256$ & & & $\mathrm{CH}_{0}: 0$ & $\mathrm{CH}_{2}: 0$ \\
& & & & $\mathrm{CH}_{2}: 0$ & \\
\hline$\varepsilon_{s s} / k_{B}(\mathrm{~K})$ & 24.0 & $194 \mathrm{~K}: 28.5$ & $194 \mathrm{~K}: 26.5$ & 28.0 & 26.0 \\
& & $273+\mathrm{K}: 28.0$ & $273+\mathrm{K}: 25.5$ & & \\
\hline
\end{tabular}


Table 2

Estimates of $-V^{e x t} / k_{B} T$ (see text) for gases on an isolated surface defined by our molecular models.

\begin{tabular}{|c|c|c|}
\hline Gas & $\mathbf{1 9 4} \mathbf{~ K}$ & $\mathbf{2 7 3} \mathbf{~ K}$ \\
\hline Carbon dioxide & & 7.0 \\
\hline Ethene & 11.3 & 8.0 \\
\hline Ethane & 11.7 & 8.3 \\
\hline Propene & & 11.7 \\
\hline Propane & & 11.8 \\
\hline
\end{tabular}


Figure captions

Figure 1. Gibbs ensemble simulation results for a) ethene, b) ethane, c) propene, and d) propane, based on the molecular models in Table 1. Solid lines (reference data[12]) and symbols (simulation data) denote saturated densities, while dotted lines[12] and symbols with error bars show saturated pressures. The saturated density error from simulation is less than or equal to the symbol size.

Figure 2. Calibration of the gas-surface interactions at 194 K. Lines are theory (fits or predictions) and symbols are experiment. Circles correspond to measured adsorption on Kureha active carbon at $194 \mathrm{~K}$. This isotherm is used to generate a PSD, which in turn is used to predict the other isotherms, via equation (1). Diamonds denote adsorption at $273 \mathrm{~K}$, while triangles are for adsorption at 298 K. Figure a) is for ethene while b) is for ethane. In Figure a) full lines correspond to predictions based on $\varepsilon_{s s} / k_{B}=28.5 \mathrm{~K}$ (see Table 1), while the dashed lines are for $28.0 \mathrm{~K}$. In Figure b) full lines correspond to predictions based on $\varepsilon_{S S} / k_{B}=26.5 \mathrm{~K}$ (see Table 1), while the dashed lines are for $25.5 \mathrm{~K}$ and the dashed-dot lines are for $\varepsilon_{s s} / k_{B}=$ 23.0 K. Pressure is on a logarithmic scale. For the inserts adsorption is also shown on a logarithmic scale.

Figure 2c. PSDs corresponding to the various values of $\varepsilon_{s s}$ for ethene and ethane in Figures 2a and $2 \mathrm{~b}$. Lines with symbols are for ethene, those without are for ethane. The solid symbols are for $\varepsilon_{s s} / k_{B}=28.5$, the open symbols are for $\varepsilon_{s s} / k_{B}=28.0$. The solid line is for $\varepsilon_{s s} / k_{B}=26.5$, the dotted line is for $\varepsilon_{s s} / k_{B}=25.5$, and the dashed-dot line is for $\varepsilon_{s s} / k_{B}=23.0$.

Figure 3. Adsorption isotherms for carbon dioxide at $273 \mathrm{~K}$ (squares and full line), ethene at $194 \mathrm{~K}$ (open circles and dotted line), ethane at $194 \mathrm{~K}$ (full circles and solid line), ethene at $273 \mathrm{~K}$ (open triangles and dotted line), ethane at $273 \mathrm{~K}$ (solid triangles and dotted line), propene at $273 \mathrm{~K}$ (open diamonds and dotted line) and propane at $273 \mathrm{~K}$ (solid diamonds and dotted line) on Kureha active carbon. Symbols are experiment, lines are fits (to ethene at 194 $\mathrm{K}$ in part a), and ethane at $194 \mathrm{~K}$ in part b)) or predictions based on the fits and the corresponding PSDs (see Figure 2c). Pressure is on a logarithmic scale. For the inserts adsorption is also shown on a logarithmic scale. 
Figure 4. Part a) is the same as Figure 3a, except that the PSD used to generate the predictions is based on a simultaneous fit to ethene at $194 \mathrm{~K}$ and carbon dioxide at $273 \mathrm{~K}$. Part b) shows the corresponding PSD. 


\section{Page 21 of 26}

Figure 1
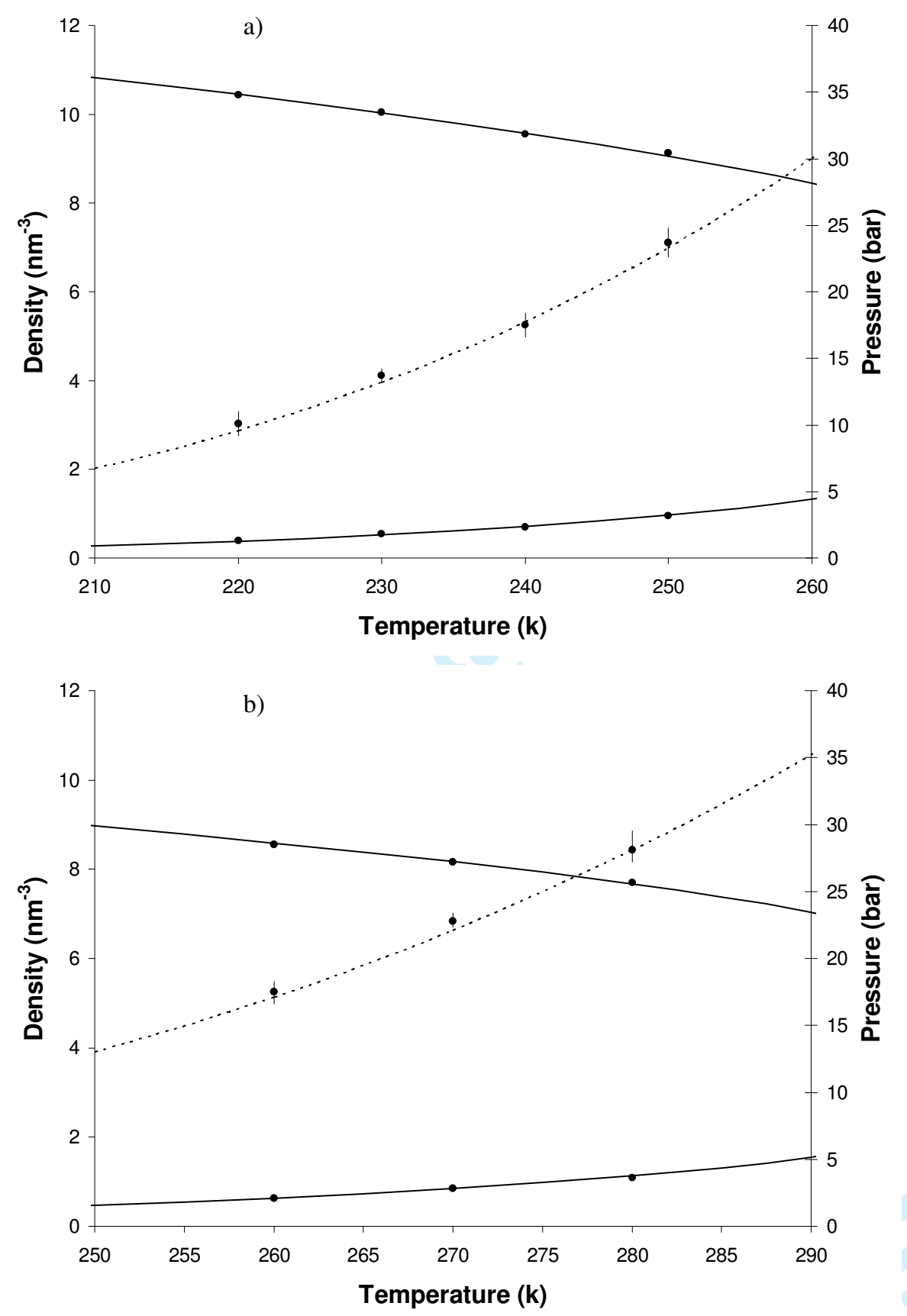

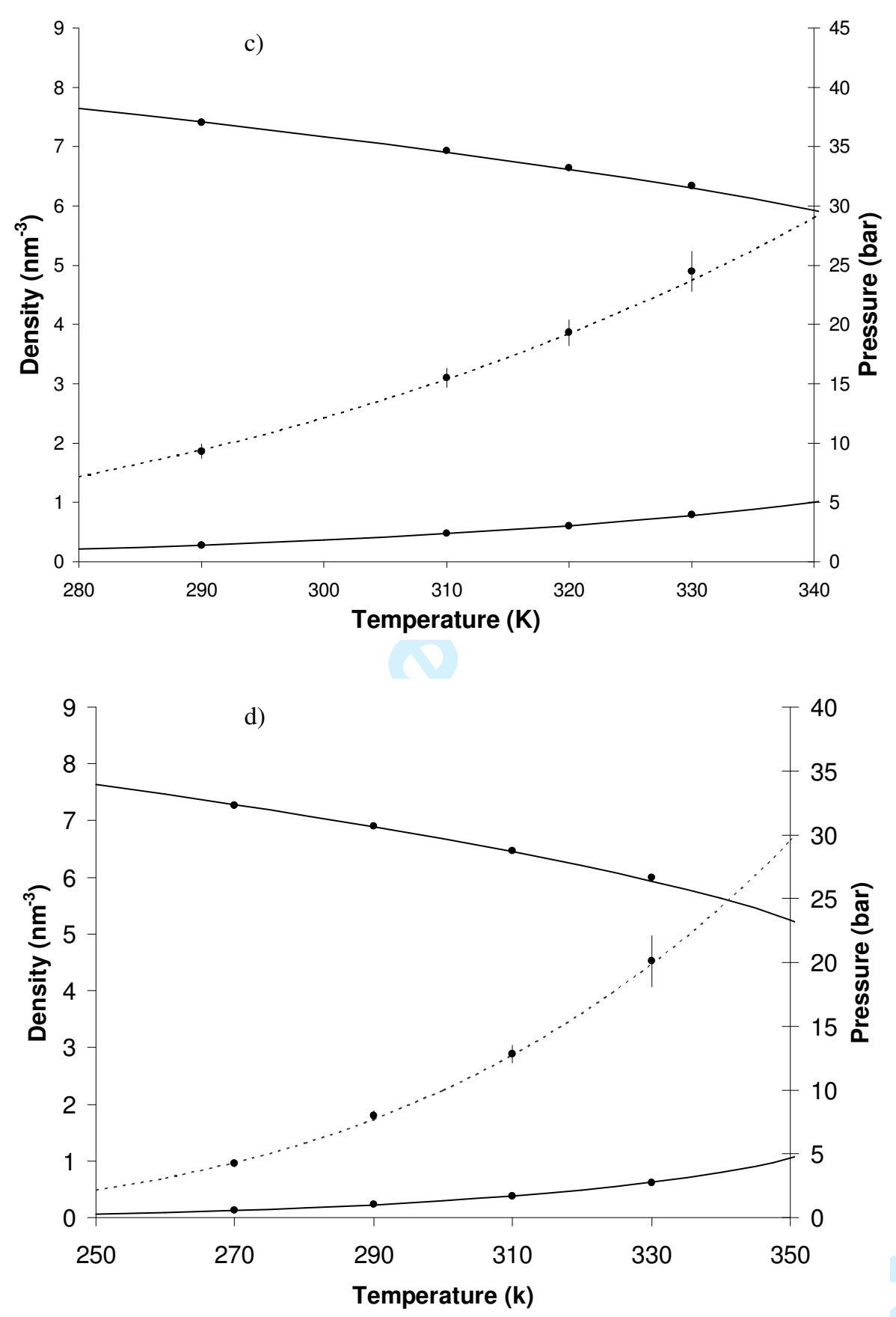


\section{Page 23 of 26}
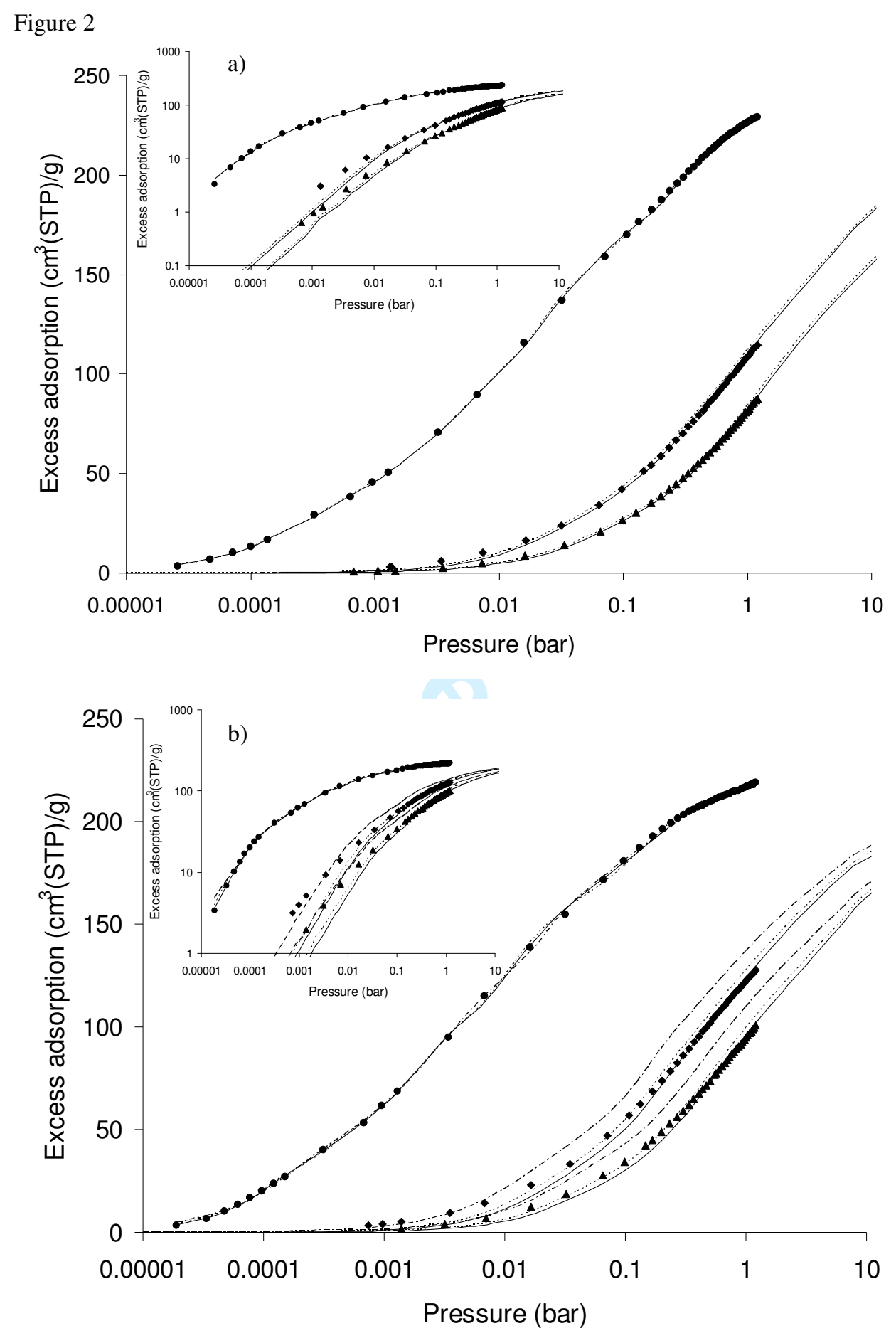


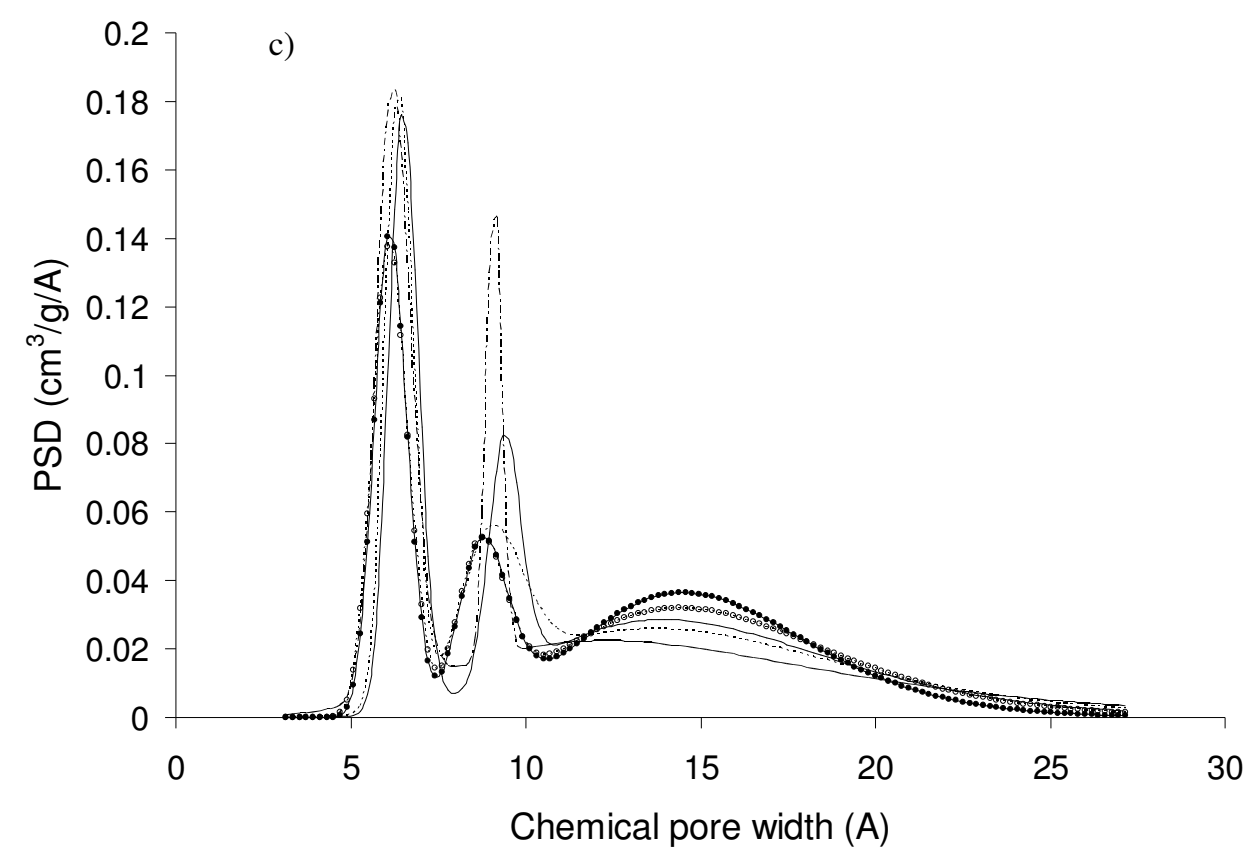




\section{Page 25 of 26}
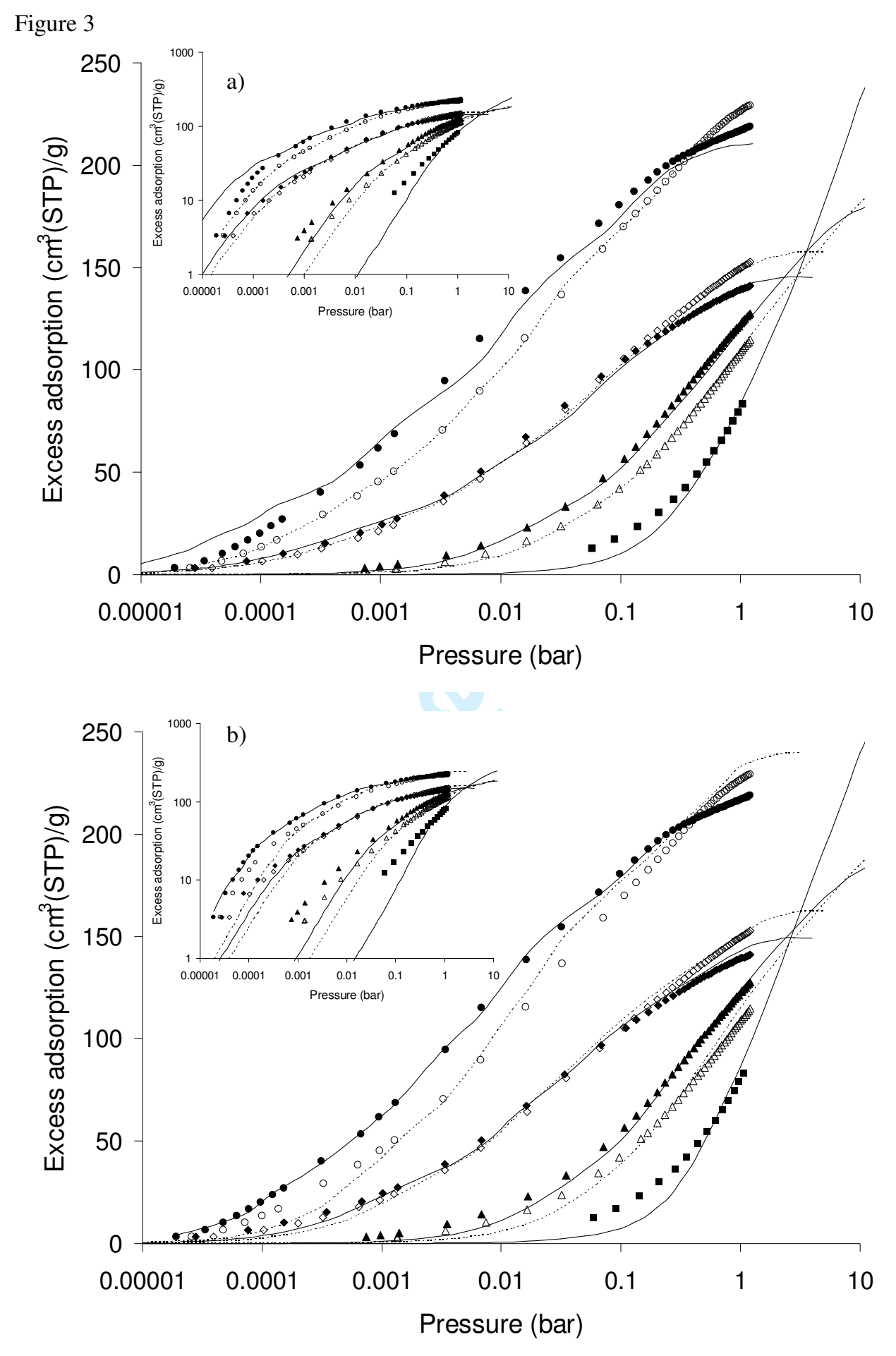
Figure 4
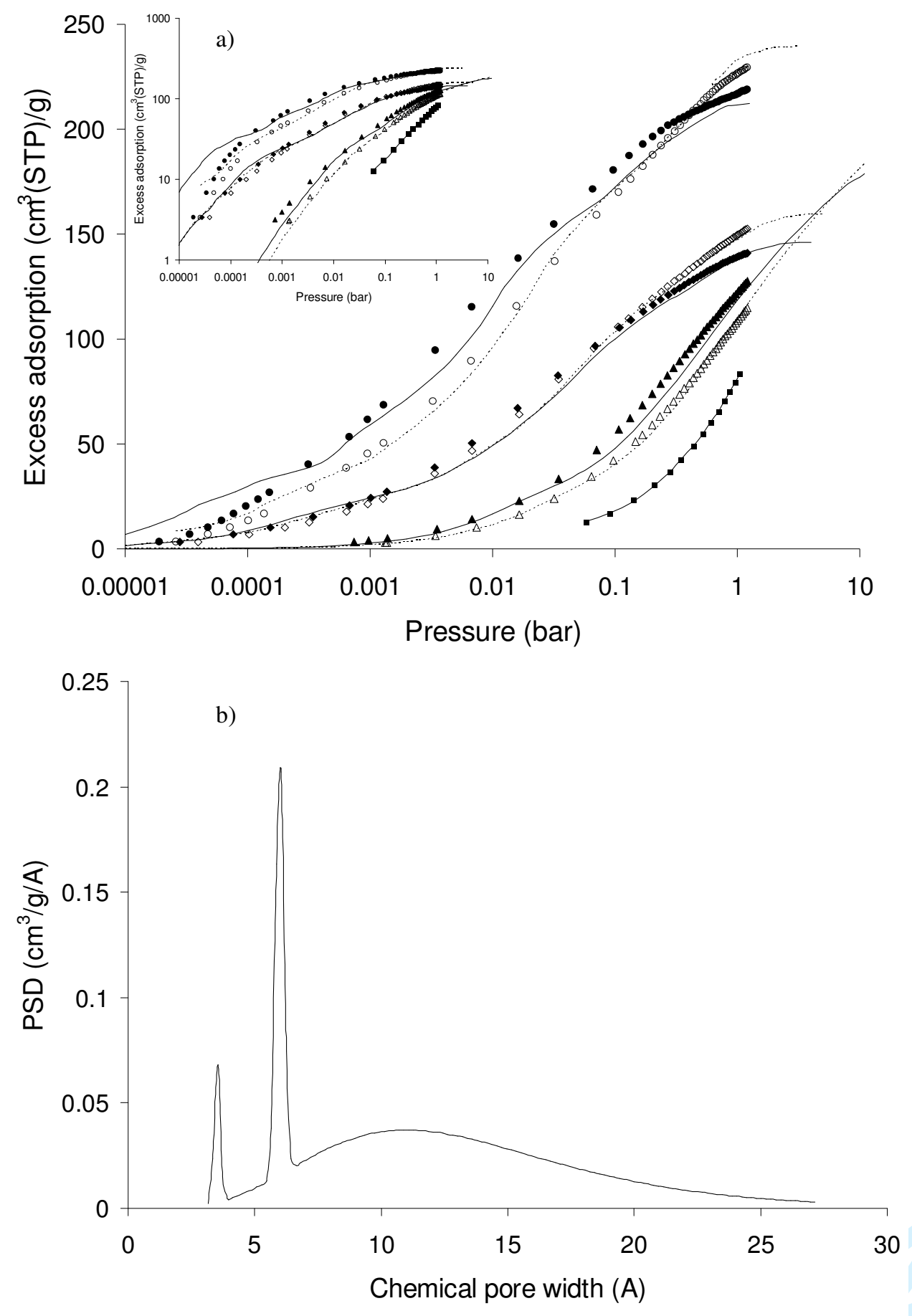